\title{
Site-specific incorporation of fluorotyrosines into the R2 subunit of $E$. coli ribonucleotide reductase by expressed protein ligation
}

\author{
Mohammad R Seyedsayamdost ${ }^{1}$, Cyril S Yee ${ }^{1} \&$ JoAnne Stubbe ${ }^{1,2}$ \\ ${ }^{1}$ Department of Chemistry, ${ }^{2}$ Department of Biology, Massachusetts Institute of Technology, 77 Massachusetts Avenue, Cambridge, Massachusetts 02139-4307, USA. \\ Correspondence should be addressed to J.S. (stubbe@mit.edu).
}

Published online 10 May 2007; doi:10.1038/nprot.2007.159

\begin{abstract}
Expressed protein ligation (EPL) allows semisynthesis of a target protein with site-specific incorporation of probes or unnatural amino acids at its $\mathrm{N}$ or $\mathrm{C}$ termini. Here, we describe the protocol that our lab has developed for incorporating fluorotyrosines $\left(\mathrm{F}_{n} \mathrm{Ys}_{\mathrm{s}}\right)$ at residue 356 of the small subunit of Escherichia coli ribonucleotide reductase using EPL. In this procedure, the majority of the protein (residues 1-353 out of 375) is fused to an intein domain and prepared by recombinant expression, yielding the protein in a thioester-activated, truncated form. The remainder of the protein, a 22-mer peptide, is prepared by solid-phase peptide synthesis and contains the $F_{n} Y$ at the desired position. Ligation of the 22-mer peptide to the thioester-activated $R 2$ and subsequent purification yield full-length $R 2$ with the $F_{n} Y$ at residue 356. The procedure to generate $100 \mathrm{mg}$ quantities of $Y_{356} F_{n} Y-R 2$ takes 3-4 months.
\end{abstract}

\section{INTRODUCTION}

Problem under investigation

The Escherichia coli ribonucleotide reductase (RNR) catalyzes the conversion of all four nucleotides to their corresponding 2'-deoxynucleotides and consists of two homodimeric subunits: R1 and R2 (refs. 1-3). R1 is the homodimeric subunit where nucleotide reduction occurs. It contains binding sites for nucleoside diphosphate substrates as well as for deoxynucleoside triphosphate and ATP allosteric effectors, which govern substrate specificity and turnover rates. R2 is the homodimeric subunit, which houses the diiron-tyrosyl radical cofactor $\left(\mathrm{Y}_{122} \bullet\right.$ ) essential for catalysis. Each turnover requires radical migration from the $\mathrm{Y}_{122} \bullet$ site on $\mathrm{R} 2$ to the active site of $\mathrm{R} 1$, over a distance of $35 \AA$. The mechanism of this long-range radical propagation event is an active area of research ${ }^{4,5}$.

Structures of active RNR, a 1:1 complex of R1 and R2, are not available. However, Uhlin and Eklund ${ }^{6}$ have generated a docking model of this complex from the individual structures of R1 and R2 (refs. 7,8). Their analysis, along with Clustal W alignments of over 160 class I RNR sequences, have suggested a pathway for reversible radical migration, which involves the following residues and perhaps the diiron center: $\left[\mathrm{Y}_{122} \leftrightarrows \mathrm{Fe}\right.$ cluster $\left.\leftrightarrows \mathrm{W}_{48} \leftrightarrows \mathrm{Y}_{356}\right]$ in $\mathrm{R} 2$ and $\left[\mathrm{Y}_{731} \leftrightarrows \mathrm{Y}_{730} \leftrightarrows \mathrm{C}_{439} \leftrightarrows\right.$ substrate] in R1 (Fig. 1) (refs. $5,6)$. Site-directed mutagenesis has been employed to provide evidence that these residues are essential for radical initiation ${ }^{9-13}$. However, these mutants have not been mechanistically informative, as they exhibit only marginal catalytic activity probably associated to residual wild-type contamination of the purified mutants. Of the 19 natural amino acids that can be substituted for Tyr at this position, only Trp and Cys have oxidation potentials close to that of Tyr, but they are poor structural substitutes ${ }^{5}$. To generate mechanistically more meaningful mutations, we aimed to replace residue $\mathrm{Y}_{356}$ on the proposed radical initiation pathway in $\mathrm{R} 2$ with unnatural amino acids that sterically resemble Tyr and have varying oxidation potentials and $\mathrm{p} K_{\mathrm{a}} \mathrm{s}$ of their phenolic side chains.

To this end, we explored the properties of $\mathrm{F}_{n} \mathrm{Ys}(n=1-4)$ and showed that they may serve as probes for disentangling the reactivities of redox-active Tyr residues in proteins (Fig. 2) (see ref. 14). $\mathrm{F}_{n}$ Ys are isosteric with tyrosine, present a range of phenolic $\mathrm{p} K_{\mathrm{a}} \mathrm{s}$ as well as a large range of oxidation potentials (Table 1). With the proper choice of $\mathrm{F}_{n} \mathrm{Y}$ and reaction $\mathrm{pH}$, one can change the protonation state of $\mathrm{F}_{n} \mathrm{Y}_{356}$, its oxidation potential or both. Thus, $\mathrm{F}_{n} \mathrm{Ys}$ are excellent probes for examining proton-coupled electron transfer mechanisms in radical propagation and should be generally useful for studying proteins that require stable or transient tyrosyl radicals for catalysis ${ }^{15,16}$. We next developed an inteinmediated semisynthesis of R2 that allows site-specific replacement of residue $\mathrm{Y}_{356}$ in $\mathrm{R} 2$ with $\mathrm{F}_{n} \mathrm{Ys}^{17,18}$.

Inteins and the mechanism of protein splicing

An intein is a protein domain that catalyzes its own post-translational self-excision from a larger polypeptide in addition to splicing of the $\mathrm{N}$ - and C-terminal domains (N-extein and C-extein) that flank the intein domain ${ }^{19,20}$. The first intein, Vma from

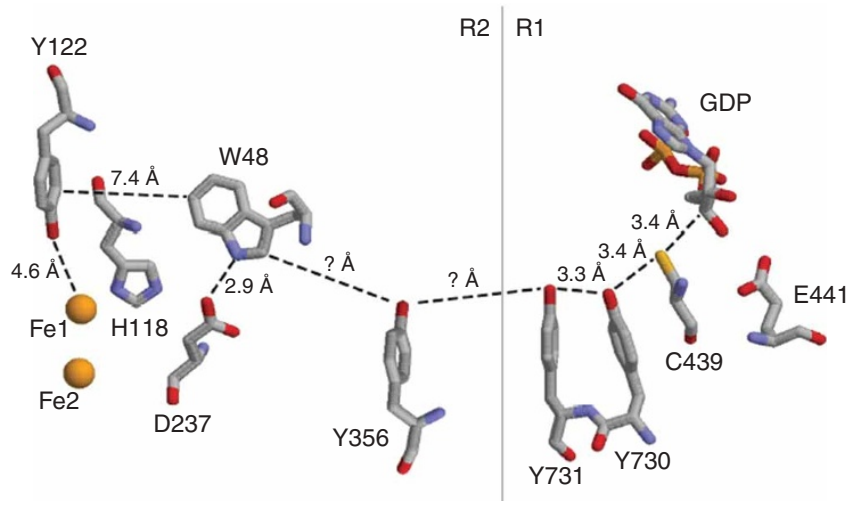

Figure 1 | Proposed radical generation pathway in $E$. coli RNR based on the docking model of Uhlin and Eklund ${ }^{6}$. Note that residue 356 is not visible in any structures of R2 owing to disorder in the C-terminal tail; therefore, the distance from $W_{48}$ and $Y_{731}$ to $Y_{356}$ is not known. Distances in R1 are based on the structure of R1 in ref. 6 and those in R2 are based on the high-resolution structure in ref. 8. 
Saccharomyces cerevisiae, was discovered in the early 1990s (ref. 21). The potential usefulness of self-splicing in protein engineering fueled detailed studies of the mechanism of action of this multistep process. This understanding led to the development of a number of re-engineered intein constructs that are now commercially available allowing semisynthesis of proteins ${ }^{22,23}$ and consequently sitespecific incorporation of unnatural amino acids. One of these techniques, EPL, is the focus of this protocol.

To demonstrate how EPL works, first the mechanism of intein self-expulsion must be outlined. The proposed mechanism for the S. cerevisiae Vma intein is shown in Figure 3 (see refs. 24,25). Splicing is initiated by an N-S acyl shift that converts a peptide bond into a thioester at the $\mathrm{N}$-extein junction site. Transthioesterification via the C-extein Cys residue results in a branched intermediate. This intermediate undergoes excision of the intein domain by attack of an Asn residue on the peptide bond at the $\mathrm{C}$-extein junction site forming an intein succinimide and the spliced extein domains. Spontaneous S-N acyl rearrangement generates the ligated $\mathrm{N}$ - and $\mathrm{C}$-exteins connected via an amide bond.

\section{Semisynthesis of R2 using EPL}

We have applied EPL to make the R2 subunit of E. coli RNR semisynthetically. R2 is a homodimer with each polypeptide containing 375 amino acids. The C-terminal 35 amino acids of E. coli $\mathrm{R} 2$ are disordered and this region houses $\mathrm{Y}_{356}$, a residue proposed to be important in the mechanistically unusual radical propagation process described above (Fig. 1) (ref. 5). The general scheme that we have used for R2 semisynthesis is shown in Figure 4 (see ref. 17). Residues 1-353, folded into a native state, are made via recombinant DNA technology and are ligated to residues 354-375, made by solid-phase peptide synthesis (SPPS). The majority of R2 (residues 1-353) is fused to an intein mutant, which lacks the C-extein Asn and Cys residues but contains a purification tag, the chitin-binding domain $(\mathrm{CBD})^{26}$. After recombinant expression, the engineered intein-fusion product catalyzes the first step of the self-cleavage reaction, but not the ensuing splicing steps. The thioester formed is then captured by a small molecule thiol, such as 2-mercaptoethanesulfonic acid (MESNA), via transthiosesterification, resulting in cleavage of the target protein from the intein-CBD construct. The thioester-activated, truncated R2 is then ligated to the remainder of R2, a peptide containing residues 354-375 with the unnatural amino acid at residue 356 and a Cys at its $\mathrm{N}$ terminus (residue 354). Transthioesterification of the N-terminal Cys residue of the peptide followed by a spontaneous $\mathrm{S}-\mathrm{N}$ acyl shift yields full-length R2. Wild-type R2 contains a Ser at 354 and thus a second mutation,

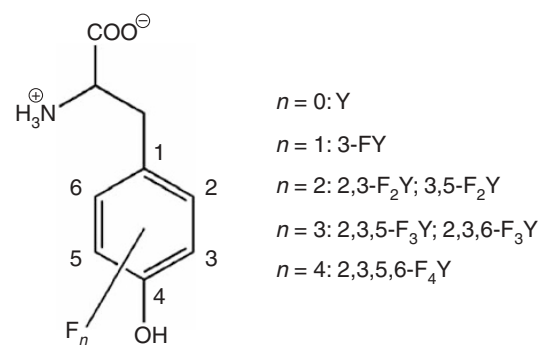

Figure 2 | Fluorotyrosine analogues. The pertinent physical and chemical properties of the $\mathrm{N}$-acetyl, $\mathrm{C}$-amide-protected variants of these $\mathrm{F}_{n} \mathrm{Ys}_{\mathrm{s}}$ are listed in Table 1 (see ref. 14).

in addition to the unnatural amino acid, is introduced into R2 at residue 354 . Finally, a third mutation, $V_{353} G$, is required to increase the efficiency of the ligation and consequently the yields to $100 \mathrm{mg}$ quantities of semisynthetic R2 necessary for biophysical experiments.

\section{Advantages and limitations of EPL}

A number of methods are in the process of being developed for the incorporation of unnatural amino acids into proteins in a robust fashion $^{27,28}$. We have chosen EPL for the semisynthesis of R2 for a number of reasons. First, $100 \mathrm{mg}$ quantities of semisynthetic R2, necessary for mechanistic biophysical experiments, are accessible. Second, purification with the CBD tag is robust. Third, residue $\mathrm{Y}_{356}$, a member of the radical initiation chain and of great interest to us mechanistically (Fig. 1), is at the disordered C-terminal tail of the protein, and therefore a good target for substitution by EPL. Finally, a number of inteins are now commercially available. As shown in Figure 4, we have used the thiol method to cleave the activated-truncated R2 from the intein-CBD construct, but temperature- and $\mathrm{pH}$-induced cleavage may also be used to generate the desired species. Because of these advantages, the EPL method has been used by numerous investigators, and excellent reviews on its applications are available ${ }^{29-31}$.

EPL also has a number of limitations. First, site-specific incorporation of probes can only occur close to the $\mathrm{N}$ or $\mathrm{C}$ termini of the protein because peptides longer than $40-50$ residues are difficult to synthesize and purify. Second, the site of ligation must be accessible to solvent in the native protein. If the site of ligation is buried, then the ligation reaction needs to be carried out under denaturing conditions, and methods to refold the protein are required. Third, the thioester-truncated protein undergoes hydrolysis in competition with ligation to the peptide. The rate of ligation, a bimolecular reaction, is elevated by increasing concentrations. However, the

TABLE 1 | Physical and chemical properties of Tyr and $F_{n} Y$ analogues.

\begin{tabular}{|c|c|c|c|c|c|c|}
\hline Derivative & $\begin{array}{c}\lambda_{\max }\left(\mathrm{F}_{n} \mathrm{Y}\right)(\mathrm{nm}) \\
\left(\varepsilon / \mathrm{M}^{-1} \mathrm{~cm}^{-1}\right)\end{array}$ & $\begin{array}{c}\lambda_{\max }\left(F_{n} Y^{-}\right)(\mathrm{nm}) \\
\left(\varepsilon / M^{-1} \mathrm{~cm}^{-1}\right)\end{array}$ & $\begin{array}{c}\lambda_{\max }\left(F_{n} \mathrm{Y} \bullet\right) \\
(\mathrm{nm})\end{array}$ & $\mathrm{p} K_{\mathrm{a}}^{\mathrm{a}}$ & $\mathrm{p} K_{\mathrm{a}}^{\mathrm{b}}$ & $\begin{array}{c}E_{\mathrm{p}}\left(\mathrm{Y} \bullet / \mathrm{Y}^{-}\right) \\
(\mathrm{mV})^{\mathrm{c}}\end{array}$ \\
\hline $\bar{Y}$ & $275(1,400)$ & $293(2,420)$ & 407 & 10 & 9.9 & 642 \\
\hline $3-F Y$ & $272(1,530)$ & $289(2,740)$ & 400 & 8.4 & 8.4 & 705 \\
\hline $2,3-F_{2} Y$ & $265(910)$ & $279(2,060)$ & 408 & 7.6 & 7.8 & 810 \\
\hline $2,3,5-\mathrm{F}_{3} \mathrm{Y}$ & $267(570)$ & $276(1,460)$ & 400 & 6.1 & 6.4 & 853 \\
\hline $2,3,6-F_{3} Y$ & $266(1,050)$ & $277(2,360)$ & 415 & 6.6 & 7.0 & 911 \\
\hline
\end{tabular}

The properties listed are for the $\mathrm{N}$-acetyl, $\mathrm{C}$-amide-protected amino acids ${ }^{14}$. ${ }^{\mathrm{a}} \mathrm{p} K_{\mathrm{a}}$ of free tyrosine and $\mathrm{F}_{n} \mathrm{Y}$ analogues. ${ }^{\mathrm{b}} \mathrm{p} K_{\mathrm{a}}$ of $\mathrm{N}$-acetyl, C-amide-protected tyrosine and $\mathrm{F}_{n} \mathrm{Y}$ analogues. ${ }^{\mathrm{C} P e a k}$ reduction potential for the $\mathrm{Y} \bullet / \mathrm{Y}^{-}$and $\mathrm{F}_{n} \mathrm{Y} \bullet / \mathrm{F}_{n} \mathrm{Y}^{-}$couples measured by differential pulse voltammetry. 
ligation is still slow and consequently hydrolysis almost always accompanies the desired reaction. Methods are thus required to separate the truncated protein from the full-length, ligated protein. This problem is aggravated if the protein of interest is multimeric, as in the case of $\mathrm{R} 2$.

Problems specifically associated with the semisynthesis of R2 R2 is a homodimer and therefore methods were required to separate the truncated homodimer, the heterodimer and the fulllength homodimer. In addition, R2 contains a diferric- $\mathrm{Y}_{122} \bullet$ cofactor, which is essential for catalysis and is susceptible to reduction by thiols. The semisynthesis, in turn, requires high thiol concentrations for cleavage of the intein-CBD domain from truncated R2 as well as for the ligation reaction. Therefore, our initial semisyntheses of $\mathrm{R} 2$ contained low $\mathrm{Y}_{122} \bullet$ content and thus low enzymatic activities. However, we have succeeded in modifying the EPL method for R2 semisynthesis so that yields of $\mathrm{Y}_{122} \bullet$ are now similar to those in recombinantly expressed wild-type R2 (M.R.S., C.S.Y. \& J.S., manuscript in preparation-detailed protocol available upon request). It is hoped that other researchers who wish to use EPL to semisynthesize their target protein to incorporate $\mathrm{F}_{n} \mathrm{Ys}$ will benefit from the detailed procedures described herein and from solutions we have found for the additional problems posed by the multimeric nature of R2, its inability to refold after denaturation and its unstable Y122• under reducing conditions.

\section{Schematic overview of the protocol}

The procedure for incorporation of $\mathrm{F}_{n}$ Ys into R2 by EPL requires the implementation of three steps that can be regarded as mutually independent sequential protocol blocks:

1. Synthesis and purification of $\mathrm{F}_{n} \mathrm{Y}(\mathrm{s})$. This block is covered in Steps 1-9 of PROCEDURE.

2. Protection of the amino group of $\mathrm{F}_{n} \mathrm{Y}(\mathrm{s})$ with the 9-fluorenylmethoxy carbonyl (Fmoc)-protecting group and synthesis and

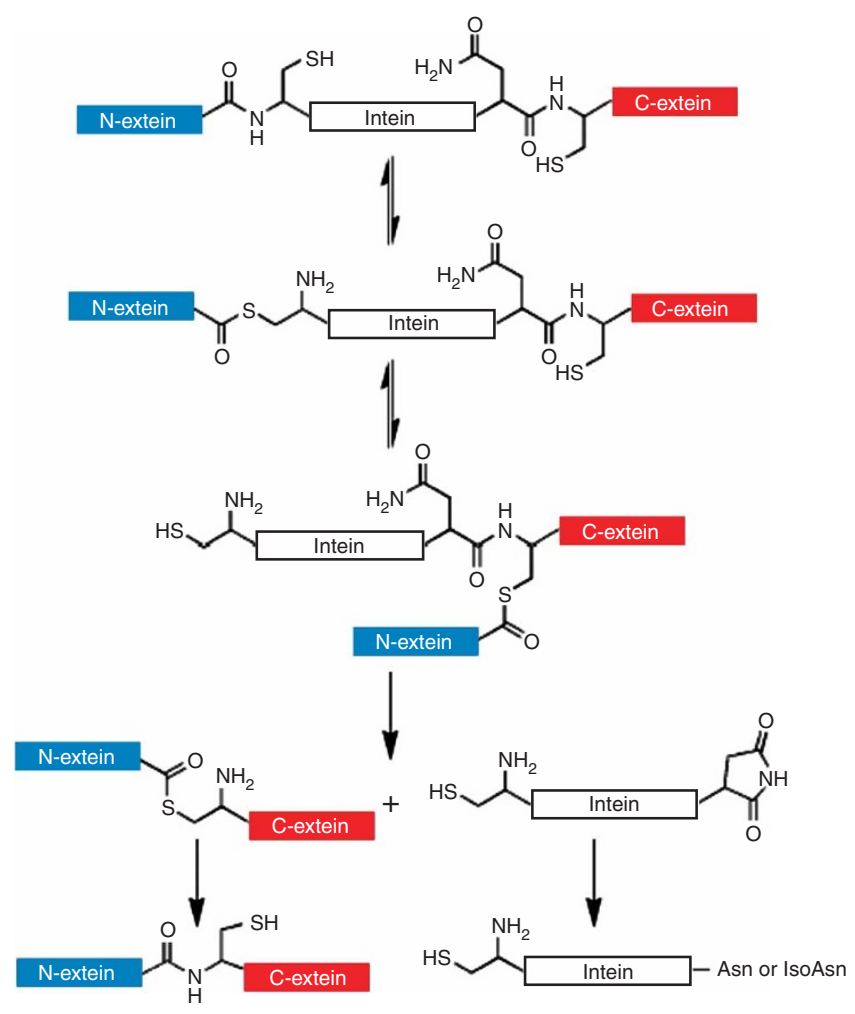

Figure 3 | Proposed mechanism of intein self-expulsion for the S. cerevisiae Vma intein ${ }^{24}$.

purification of the peptide-22mer $\left(\mathrm{H}_{2} \mathrm{~N}-\mathrm{CS}\left(\mathrm{F}_{n} \mathrm{Y}\right)\right.$ LVGQIDSEVD TDDLSNFQL-COOH) containing desired $\mathrm{F}_{n} \mathrm{Y}(\mathrm{s})$, Steps 10-34.

3. Growth of MESNA-activated, truncated R2 and ligation to the $\mathrm{F}_{n} \mathrm{Y}-22 \mathrm{mer}(\mathrm{s})$, Steps 35-50.

\section{MATERIALS}

\section{REAGENTS}

Note that all purchased chemicals should be of highest available grade from the indicated vendor. It is furthermore common practice to be familiar with the properties and potential hazards of each chemical used - these may be obtained from material safety data sheets (e.g., http://hazard.com/msds).

- Tyrosine phenol lyase (TPL): the expression and purification of TPL from the pTZTPL plasmid has been reported previously ${ }^{32-34}$

- Ammonium acetate (Sigma-Aldrich)

- Pyruvic acid (Sigma-Aldrich)

- Pyridoxal-5'-phosphate (PLP) (Sigma-Aldrich) $\Delta$ CRITICAL PLP must be stored dry in the dark at $-20{ }^{\circ} \mathrm{C}$.

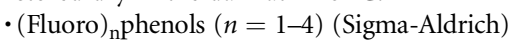

- Ninhydrin (Sigma-Aldrich)

- $n$-butanol (Sigma-Aldrich)

- Celite 545 (Sigma-Aldrich)

- $\beta$-Mercaptoethanol ( $\beta \mathrm{ME})$ (Mallinckrodt)

-Ethyl acetate (Mallinckrodt) ! CAUTION Ethyl acetate is flammable-keep

away from sources of ignition.

- Acetic acid (Mallinckrodt)! CAUTION Acetic acid is corrosive.

- Sodium chloride $(\mathrm{NaCl})$ (Mallinckrodt)

$\cdot \mathrm{HCl}$ solution $(\sim 6 \mathrm{~N})$

- Cation exchange resin hydrogen form, AG50W-X8, 50-100 mesh (Bio-Rad)

$\cdot 10 \%(\mathrm{v} / \mathrm{v})$ ammonium hydroxide solution

- Sodium carbonate $\left(\mathrm{Na}_{2} \mathrm{CO}_{3}\right)$ (Sigma-Aldrich)

-9-fluorenylmethyl $\mathrm{N}$-succinimidyl carbonate (Fmoc-OSu) (Sigma-Aldrich)

$\Delta$ CRITICAL Fmoc-OSu must be stored dry at $-20{ }^{\circ} \mathrm{C}$.
- Dioxane (Sigma-Aldrich)

- Diisopropyl ethylamine (DIPEA) (Sigma-Aldrich)

- Dimethyl formamide (DMF) (Sigma-Aldrich)! CAUTION DMF is

flammable and a strong irritant.

- Piperidine (Sigma-Aldrich) ! CAUTION Piperidine is a mutagen and a

reproductive toxin.

- Trifluoroacetic acid (TFA) (Sigma-Aldrich) ! CAUTION TFA is highly

corrosive.

- Triisopropyl silane (TIS) (Sigma-Aldrich)

- $\alpha$-Cyano-4-hydroxycinnamic acid (CHA) and matrix-assisted laser desorption/ionization time of flight (MALDI TOF) standards: angiotensin, P14R synthetic peptide, adrenocorticotropic hormone fragment and oxidized $\mathrm{B}$ chain insulin (Sigma-Aldrich)

- Chloroform $\left(\mathrm{CHCl}_{3}\right)$ (Mallinckrodt) ! CAUTION $\mathrm{CHCl}_{3}$ is a reproductive toxin and a probable human carcinogen.

- Methanol (Mallinckrodt) ! CAUTION Methanol is highly flammable and an irritant.

- Acetonitrile (MeCN) (Mallinckrodt) ! CAUTION MeCN is flammable and a possible mutagen.

- Dichloromethane $\left(\mathrm{CH}_{2} \mathrm{Cl}_{2}\right)$ (Mallinckrodt)! CAUTION $\mathrm{CH}_{2} \mathrm{Cl}_{2}$ is a potential carcinogen.

- Diethyl ether (Mallinckrodt) ! CAUTION Diethyl ether is an irritant and

highly flammable.

- Magnesium sulfate $\left(\mathrm{MgSO}_{4}\right)$ (Mallinckrodt)

- $\mathrm{NaCl}$ (Mallinckrodt)

-Ammonium bicarbonate $\left(\mathrm{NH}_{4} \mathrm{HCO}_{3}\right)$ (Mallinckrodt) 
Figure 4 | Semisynthesis of R2 via EPL ${ }^{17 .}$ Residues 1-353 are expressed recombinantly as an intein-CBD chimera. After the initial N-S acyl shift, the small molecule thiol, MESNA, is used to cleave the truncated R2 from the intein-CBD domain. The resulting MESNA-activated R2 is ligated to the $F_{n} Y-22 m e r$, which is prepared by SPPS and contains residues 354-375 with the $F_{n} Y$ at residue 356 . Note that the $V_{353} G$ mutation was necessary to increase cleavage and ligation yields.

- Potassium phosphate (KPi) (Mallinckrodt)

- Silica gel 60 (particle size 0.04-0.063 mm, 230-400 mesh) (EMD Bioscience) - $O$-(7-azabenzotriazole-1-yl)- $N, N, N^{\prime}, N^{\prime}$, tetramethyluronium hexafluorophosphate (HATU) (Applied BioSystems) $\Delta$ CRITICAL HATU must be stored dry at $<5{ }^{\circ} \mathrm{C}$.

-Fmoc-L-Leu-PEG-PS $\left(0.2 \mathrm{mmol} \mathrm{g}^{-1}\right)$ (Applied BioSystems)

-Fmoc-Leu-OH (NovaBiochem)

- Fmoc-Gln(Trt)-OH (NovaBiochem)

- Fmoc-Phe-OH (NovaBiochem)

- Fmoc-Asn(Trt)-OH (NovaBiochem)

- Fmoc-Ser(OtBu)-OH (NovaBiochem)

- Fmoc-Asp(OtBu)-OH (NovaBiochem)

- Fmoc-Thr(OtBu)-OH (NovaBiochem)

- Fmoc-Val-OH (NovaBiochem)

- Fmoc-Glu(OtBu)-OH (NovaBiochem)

- Fmoc-Asp(OtBu)-OH (NovaBiochem)

- Fmoc-Ile-OH (NovaBiochem)

- Fmoc-Gly-OH (NovaBiochem)

- Fmoc-Asp (OtBu)-Ser( $\psi^{\mathrm{Me}, \mathrm{Me}}$ pro)-OH (NovaBiochem)

- Fmoc-Cys ('Buthio)-OPfp (NovaBiochem)

-1-hydroxy-benzotriazole hydrate (HOBt) (NovaBiochem)

- $\mathrm{F}_{n}$ Ys from the previous step

-BL21-DE3 codon+ cells (Stratagene)

-R2-intein-CBD plasmid ${ }^{17}$

-Luria-Bertani medium (LB) (Becton Dickerson)

- Isopropyl- $\beta$-D-thiogalactopyranoside (IPTG; Promega)

- DL-Dithiothreitol (DTT) (Promega)

- MESNA (Sigma-Aldrich)

- Ampicillin (Amp) (Sigma-Aldrich)

- Chloramphenicol (Cm) (Sigma-Aldrich)

-Triton X-100 (Sigma-Aldrich)

- Sephadex G-25 (Sigma-Aldrich)

-Phenylmethanesulfonyl fluoride (PMSF) (Sigma-Aldrich) ! CAUTION PMSF is toxic.

- Glycerol (Sigma-Aldrich)

- Bradford Reagent (Sigma-Aldrich)

- Sodium ascorbate (Sigma-Aldrich)

- Iron ammonium sulfate hexahydrate $\left(\mathrm{Fe}^{\mathrm{II}}\left(\mathrm{NH}_{4}\right)_{2}\left(\mathrm{SO}_{4}\right)_{2}\right)$ (Sigma-Aldrich)

-Ethylenediamine tetraacetic acid (EDTA) (Sigma-Aldrich) ! CAUTION EDTA

is an irritant.

- Chitin beads (NEB)

-4-(2-hydroxyethyl)piperazine-1-ethanesulfonic acid (HEPES) (EMD

Bioscience)

- DNase I (from bovine pancreas) (Roche)

- Tris(hydroxymethyl)aminomethane (Tris base) (Roche)

\section{EQUIPMENT}

- Large separatory funnel (2 liters)

- Large Buchner funnel (1 liter)

- Stir plate

- Rotary evaporator

- Lyophilizer

- Thin-layer chromatography (TLC) plates-2.5 × $7.5 \mathrm{~cm}$ (J.T. Baker)

- Pioneer Peptide Synthesizer (Applied Biosystems)

- Disposable Fritted Econo-Pac Columns (Bio-Rad)

- Vortexer (Fisher Scientific)

- HPLC system with a 2487 dual absorption detector and 515 HPLC pumps running on millennium software (Waters)

- Semi-preparative XTerra MS $C_{18} 5 \mu \mathrm{m}(19 \times 100 \mathrm{~mm})$ column (Waters)

- Analytical Phenomenex C18 $5 \mu \mathrm{m}$ (150 x $4.6 \mathrm{~mm})$ column (Jupiter)

$\cdot 1,000 \mathrm{Da}$ cutoff dialysis tubing (SpectraPor)

$.50 \mathrm{ml}$ polypropylene Falcon tubes (BD Bioscience)
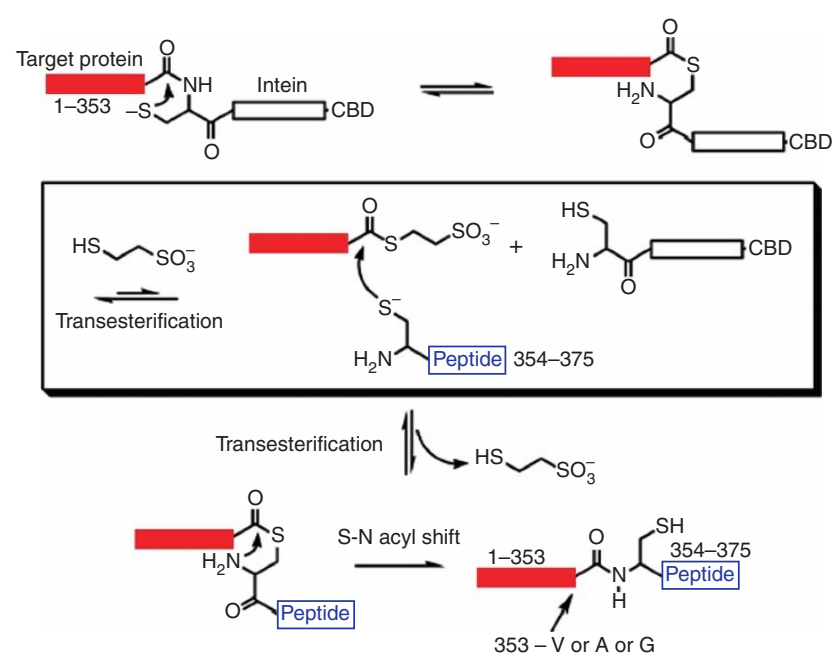

-Shaker/incubator (New Brunswick Scientific)

- French Pressure Cell Press (Sim-Aminco Spectronic Instruments)

- Glove Box (M. Braun)

- SDS-PAGE setup (Bio-Rad)

- Sprint Biocad FPLC system (Applied Biosystems)

- MonoQ HR 16/10 Anion Exchange column $(10 \mu \mathrm{m}, 2 \times 10.5 \mathrm{~cm}, 33 \mathrm{ml})$ (Amersham Bioscience)

- Centriprep protein concentration device (YM-30) (Millipore)

- Amicon ultrafiltration device (Millipore)

- YM-30 ultrafiltration membranes (Millipore)

- OmniFlex MALDI TOF mass spectrometer and corresponding target (Bruker)

\section{REAGENT SETUP}

Ninhydrin test To test for the presence of free amines, a ninhydrin solution consisting of $0.19 \%(\mathrm{w} / \mathrm{v})$ ninhydrin, $95 \%(\mathrm{v} / \mathrm{v}) n$-butanol, $0.5 \%(\mathrm{v} / \mathrm{v})$ acetic acid and $4.5 \%(\mathrm{v} / \mathrm{v})$ water must be prepared. To perform a ninhydrin test, spot a drop of the solution onto a TLC plate and allow the plate to dry. Dip the TLC plate into the ninhydrin solution, then heat the plate with a heat gun for 10-15 s. A purple/pink spot constitutes a positive result and indicates the presence of a free amine functionality.

TPL activity Before synthesis of $\mathrm{F}_{n} \mathrm{Ys}$, the activity of the purified TPL should be determined by previously reported methods ${ }^{32,33}$. One unit of TPL activity $(\mathrm{U})$ is defined as $1 \mu \mathrm{mol}$ product per min. Purified TPL in our hands has a specific activity of $6-10 \mathrm{U} \mathrm{mg}^{-1}$.

MALDI TOF MS Mass spectra are obtained under negative mode using $\mathrm{CHA}$ as the matrix. The matrix is prepared by suspending $10 \mathrm{mg}$ of CHA into a $1 \mathrm{ml}$ solution of $50 \%(\mathrm{v} / \mathrm{v}) \mathrm{MeCN}$ and $0.1 \%(\mathrm{v} / \mathrm{v})$ TFA $-1 \mu \mathrm{l}$ of the peptide $(0.5-$ $3 \mathrm{mM}$ ) solution is then co-spotted with $1 \mu \mathrm{l}$ of matrix solution onto the MALDI TOF target and allowed to dry for $0.5-1 \mathrm{~h}$ before analysis. The MALDI TOF mass spectrometer is calibrated with a mixture of angiotensin II $(1,044.5423 \mathrm{Da}), \mathrm{P} 14 \mathrm{R}$ synthetic peptide $(1,531.8582 \mathrm{Da})$, adrenocorticotropic hormone fragment $(2,463.1989 \mathrm{Da})$ and insulin, oxidized B chain $(3,492.6513 \mathrm{Da})$ under negative mode.

Purification buffers The lysis buffer for isolation of MESNA-activated, truncated R2 consists of $30 \mathrm{mM}$ HEPES, $500 \mathrm{mM} \mathrm{NaCl}$ and $0.1 \%$ (w/v) Triton $\mathrm{X}-100$ ( $\mathrm{pH}$ 7.6). Before cell lysis, supplement the lysis buffer with $25 \mathrm{U}$ DNase I per gram of cell paste and $1 \mathrm{mM}$ PMSF. The cleavage buffer consists of $50 \mathrm{mM}$ HEPES and $500 \mathrm{mM} \mathrm{NaCl}$ (pH 7.6).

EQUIPMENT SETUP

Manual SPPS Manual deblocking and coupling reactions are performed on a vortexer fitted with an adapter suitable for holding $50 \mathrm{ml}$ Falcon tubes, which in turn hold the fritted Econo-pac columns.

Anaerobic dialysis To maintain a low oxygen concentration during dialysis, the buffer is bubbled with argon gas for $15 \mathrm{~min}$ before immersion of the dialysis bag and continuously thereafter. Anaerobic dialysis is performed in an Erlenmeyer flask at room temperature $\left(25^{\circ} \mathrm{C}\right)$.

Pre-equilibration of chitin column A total of $5 \mathrm{ml}$ of chitin resin is required per gram of wet cell paste. For $200 \mathrm{ml}$ of chitin resin, a column with dimensions of $5 \times 10 \mathrm{~cm}$ is used. Equilibrate the chitin column with 10 column volumes (CVs) of lysis buffer before application of the crude extract. After use, the 
column should be washed with $10 \mathrm{CV}$ of water, $5 \mathrm{CV}$ of a $1 \%(\mathrm{w} / \mathrm{v})$ SDS solution followed by $20 \mathrm{CV}$ of water. The resin should be stored in a $20 \%(\mathrm{v} / \mathrm{v})$ ethanol solution at $4{ }^{\circ} \mathrm{C}$.

Mono $Q$ anion exchange separation of the ligation mixture Mono $Q$ column chromatography is carried out at a flow rate of $3 \mathrm{ml} \mathrm{min}^{-1}$. The column is equilibrated in $50 \mathrm{mM}$ Tris, 5\% glycerol and $1 \mathrm{mM}$ DTT, pH 7.6 (Buffer Q). After loading, the column is washed for 2 min with Buffer Q. The protein is then eluted using a linear gradient from 0 to $200 \mathrm{mM} \mathrm{NaCl}$ in Buffer Q over $3 \mathrm{~min}$, followed by a linear gradient from 200 to $440 \mathrm{mM} \mathrm{NaCl}$ in Buffer Q over $37 \mathrm{~min}$. Full-length R2 typically elutes at $360-380 \mathrm{mM} \mathrm{NaCl}$ in Buffer Q.

\section{PROCEDURE}

\section{Synthesis of $F_{n} Y(s) \bigcirc$ TIMING 1-4 weeks}

1| Make a 1 liter solution of $30 \mathrm{mM}$ ammonium acetate. Add the appropriate fluorophenol to a final concentration of $10 \mathrm{mM}$. Then, add pyruvic acid and $\beta M E$ to final concentrations of 60 and $5 \mathrm{mM}$, respectively.

$\triangle$ CRITICAL STEP Fluorophenol concentrations in excess of $10 \mathrm{mM}$ result in enzyme denaturation. Ensure that the concentration of (fluoro) ${ }_{\mathrm{n}}$ phenol is $\leq 10 \mathrm{mM}$.

2| Adjust the $\mathrm{pH}$ of the solution to 8.0 with ammonium hydroxide. Protect the reaction vessel from light by wrapping it with aluminum foil, as the PLP cofactor used by TPL is light-sensitive.

3| For the synthesis of all fluorophenols other than 2,3,5,6-tetrafluorophenol, follow option A; otherwise, follow directions in option B:

Option (A)

(i) Add $30 \mathrm{U}$ of TPL and PLP to a final concentration of $40 \mu \mathrm{M}$.

- PAUSE POINT Stir for 3-4 days at room temperature.

$\triangle$ CRITICAL STEP The vessel should remain covered with aluminum foil during this process to avoid light-induced PLP degradation. Option (B)

(i) For 2,3,5,6-tetrafluorophenol, add $300 \mathrm{U}$ of TPL and $40 \mu \mathrm{M}$ PLP.

PAUSE POINT Stir for 3-4 weeks. The vessel should remain covered with aluminum foil during this period (see above). Every week, supplement the mixture with an additional $20 \mathrm{U}$ of TPL and $1 \mathrm{mM}$ of 2,3,5,6-tetrafluorophenol.

4| Before the work-up procedure, the cation exchange resin needs to be prepared. For a 1 liter reaction, use $220 \mathrm{ml}$ of cation exchange resin in a column with dimensions of $4 \times 17 \mathrm{~cm}$. New resin in the protonated form $\left(\mathrm{H}^{+}\right.$form) may be used after washing with $10 \mathrm{CV}$ of water. After each application, the resin should be cleaned and returned to the protonated form. For this purpose, instructions by the manufacturer should be followed.

5 After completion of the TPL-mediated formation of $\mathrm{F}_{n} \mathrm{Y}$, remove the aluminum foil and lower the $\mathrm{pH}$ of the mixture to 2-3 with $6 \mathrm{~N} \mathrm{HCl}$. This results in precipitation of TPL.

6| Prepare a celite pad to remove the precipitated TPL: add celite powder to a thickness of 2-3 cm in a 1 liter Buchner funnel (coarse frit) resting on a sidearm suction flask, which is connected to a vacuum line. Rinse the celite pad with $\sim 500 \mathrm{ml}$ water, then filter the mixture through the celite pad and collect the filtrate.

7| Extract the filtrate once with 0.5 volumes of ethyl acetate; separate the two layers with a separatory funnel and discard the ethyl acetate layer (top layer). Collect the aqueous layer (bottom layer), which contains the $F_{n} Y$, in a beaker.

8| Load this mixture onto the cation exchange resin prepared in Step 4 to separate $F_{n} Y$ from residual pyruvic acid, acetic acid and PLP. After loading, wash the column with 8 CV of water.

9| Elute the $\mathrm{F}_{n} \mathrm{Y}$ from the column with $\sim 8 \mathrm{CV}$ of a $10 \%$ ammonium hydroxide solution and collect $10 \mathrm{ml}$ fractions. Pool the fractions that give a positive ninhydrin test (see REAGENT SETUP) and concentrate to $20-30 \mathrm{ml}$ in vacuo using a rotary evaporator with the temperature of the water bath set at $35-40{ }^{\circ} \mathrm{C}$. Lyophilize the remaining solution to dryness and store at $4^{\circ} \mathrm{C}$. Identity of the $\mathrm{F}_{n} \mathrm{Y}$ is based on the UV properties (Table 1) and its NMR spectrum, which have been reported previously ${ }^{14}$. PAUSE POINT $F_{n} Y_{s}$ may be safely stored at $4{ }^{\circ} \mathrm{C}$ for several years.

\section{Fmoc protection of $\mathrm{F}_{n} \mathrm{Y}(\mathrm{s})$ and peptide synthesis of $\mathrm{F}_{n} \mathrm{Y}$-22mer(s) TIMING 3 weeks}

10| Addition of the Fmoc-protecting group to each $F_{n} Y$ is conveniently carried out on a $0.5-1$ mmol scale ${ }^{35}$. Dissolve $F_{n} Y$ $(1 \mathrm{mmol})$ in $3.4 \mathrm{ml}$ of a $10 \% \mathrm{Na}_{2} \mathrm{CO}_{3}$ solution.

11| Dissolve Fmoc-OSu (1.35 mmol) in $3.5 \mathrm{ml}$ of dioxane in a $100 \mathrm{ml}$ pear-shaped flask fitted with a stir bar. Cool both mixtures to $0-4{ }^{\circ} \mathrm{C}$ either by incubating on ice or stirring in a cold room.

12| In one step, add the $F_{n} Y$ solution to the Fmoc-OSu mixture while stirring, then allow the reaction to warm to room temperature. Continue stirring the mixture at room temperature and monitor the reaction progress by TLC (see Table 2 for the 
PROTOCOL

TABLE 2 | Synthesis and purification of $\mathrm{Fmoc}-\mathrm{F}_{n} \mathrm{Y}-\mathrm{OH}$ analogues ${ }^{18}$.

\begin{tabular}{|c|c|c|c|}
\hline $\mathbf{F}_{n} \mathbf{Y}$ analogue & Solvent system for silica gel purification & $R_{\mathrm{f}}$ & Yield (\%) \\
\hline Fmoc-2,3-F $\mathrm{Y}$ & $20: 1 \mathrm{CHCl}_{3} / \mathrm{MeOH}$ & 0.3 & 95 \\
\hline Fmoc-3,5- $F_{2} Y$ & $10: 1 \mathrm{CHCl}_{3} / \mathrm{MeOH}$ & 0.4 & 85 \\
\hline Fmoc- $2,3,5-\mathrm{F}_{3} \mathrm{Y}$ & $10: 1 \mathrm{CHCl}_{3} / \mathrm{MeOH}$ & 0.2 & 50 \\
\hline $\mathrm{Fmoc}-\mathrm{F}_{4} \mathrm{Y}$ & $20: 1 \mathrm{CHCl}_{3} / \mathrm{MeOH}$ & 0.2 & 82 \\
\hline
\end{tabular}

mobile phase and corresponding $R_{\mathrm{f}}$ value of each $\left.\mathrm{Fmoc}-\mathrm{F}_{n} \mathrm{Y}-\mathrm{OH}\right)$. The reaction is complete when the intensity of the spot corresponding to $\mathrm{Fmoc}-\mathrm{F}_{n} \mathrm{Y}-\mathrm{OH}$ ceases to increase.

13 After completion of the reaction, typically $0.5-2.5 \mathrm{~h}$ (higher fluorine substitution requires longer reaction times), add $36 \mathrm{ml}$ of water to the reaction and extract the mixture twice with $15 \mathrm{ml}$ of EtOAc using a separatory funnel to remove unreacted Fmoc-OSu. Discard the EtOAc layer (top layer).

14| Lower the $\mathrm{pH}$ of the aqueous phase, which contains $\mathrm{Fmoc}-\mathrm{F}_{n} \mathrm{Y}-\mathrm{OH}$, to 2-3 with $2 \mathrm{~N} \mathrm{HCl}$ and extract the product into Et0Ac $(\sim 10 \times, 15 \mathrm{ml})$. Combine the Et0Ac extracts.

15 Wash the EtOAc extracts with a saturated $\mathrm{NaCl}$ solution $(3 \times, 4 \mathrm{ml})$ and water $(2 \times, 4 \mathrm{ml})$ and dry over $\mathrm{MgSO}_{4}$ : add a spatula tip of $\mathrm{MgSO}_{4}$ to the EtOAc extract and swirl the flask. $\mathrm{MgSO}_{4}$ that absorbs water forms clumps whereas dry $\mathrm{MgSO}_{4}$ remains powder-like. Continue to add $\mathrm{MgSO}_{4}$ to the EtOAc extract with swirling until clumps of hydrated $\mathrm{MgSO}_{4}$ no longer form and $\mathrm{MgSO}_{4}$ powder settles at the bottom of the flask. At this point, remove the hydrated $\mathrm{MgSO}_{4}$ by vacuum filtration. Finally, remove the solvent in vacuo (water bath temperature set at $25^{\circ} \mathrm{C}$ ).

PAUSE POINT The product from this procedure may be stored at $-20{ }^{\circ} \mathrm{C}$ for months.

16 Purify the Fmoc- $\mathrm{F}_{n} \mathrm{Y}-\mathrm{OH}$ by silica gel chromatography $(25 \mathrm{~g}, 1.5 \times 40 \mathrm{~cm})$ using the solvent systems in Table 2. Purified Fmoc- $\mathrm{F}_{n} \mathrm{Y}-\mathrm{OH}$ can be used directly in peptide synthesis. Note that the hydroxyl group of the fluorophenol does not require protection.

PAUSE POINT The purified dry Fmoc- $\mathrm{F}_{n} \mathrm{Y}-\mathrm{OH}$ may be stored at $-20{ }^{\circ} \mathrm{C}$ for up to a year.

17| The first 19 residues $\left(\mathrm{H}_{2} \mathrm{~N}-\mathrm{L}_{19} \mathrm{VGQID}_{14} \mathrm{~S}_{13}\right.$ EVDTDDLSNFQL $\left.\mathrm{L}_{1}-\mathrm{COOH}\right)$ of $\mathrm{F}_{n} \mathrm{Y}-22$ mer are prepared on a peptide synthesizer. Note that residues 13 (Ser) and 14 (Asp) are added as a pseudo-proline dipeptide to avoid peptide aggregation (vide infra) ${ }^{36}$. The remaining three residues, $F_{n} Y_{20}, S_{21}$ and $C_{22}$, are added manually. In this manner, one can generate multiple $F_{n} Y-22$ mer peptides from the same batch of 19-mer peptide. Should only one of the $F_{n} Y_{s}$ in Figure 2 be of interest, then the entire $F_{n} Y-22$ mer may be prepared on the synthesizer. Because the mode of operation of a peptide synthesizer is brand- and model-specific, the instruction manual for the specific instrument should be followed. Synthesis of the peptide requires two steps that are repeated until the synthesis is complete. The first step is removal of the N-Fmoc-protecting group and the second step is coupling to the next $\mathrm{N}$-Fmoc-protected amino acid in the peptide sequence. Using the synthesizer, the Fmoc group is removed in DMF containing $20 \%(\mathrm{v} / \mathrm{v}$ ) piperidine and $0.1 \mathrm{M} \mathrm{HOBt}$ (see Fig. 5 and critical step below for the purpose of this reagent) for 10 min with a preset instrument flow rate. The coupling reactions utilized 4 equivalents of Fmoc-protected amino acid, 3.6 equivalents of HATU and 8 equivalents of DIPEA relative to the amount of peptide at final concentrations of $0.5,0.45$ and $1 \mathrm{M}$, respectively, and proceeded for $1 \mathrm{~h}$.

$\triangle$ CRITICAL STEP For the synthesis of the $F_{n} Y-22$ mer peptide, inclusion of HOBt in the deblocking mixture is essential for avoiding aspartimide formation resulting from the reaction sequence shown in Figure 5. Omitting HOBt during deblocking of the Fmoc group yields peptides that contain $\alpha$ - or

$\beta$-piperidides. This "side product" can constitute as much as $80 \%$ of the total peptide when deblocking is performed without $\mathrm{HOBt}^{37}$.

$\triangle$ CRITICAL STEP The pseudo-proline dipeptide, Fmoc-Asp(OtBu)-Ser( $\psi^{\mathrm{Me}}$, Mepro)- $\mathrm{OH}$, is essential for avoiding aggregation of the $\mathrm{F}_{n} \mathrm{Y}$-22mer peptide during synthesis. The $F_{n} Y$-22mer peptide is especially prone to aggregation, which results in drastically reduced deblocking and coupling yields when the peptide length exceeds 18 residues. The pseudoproline dipeptide prevents aggregation

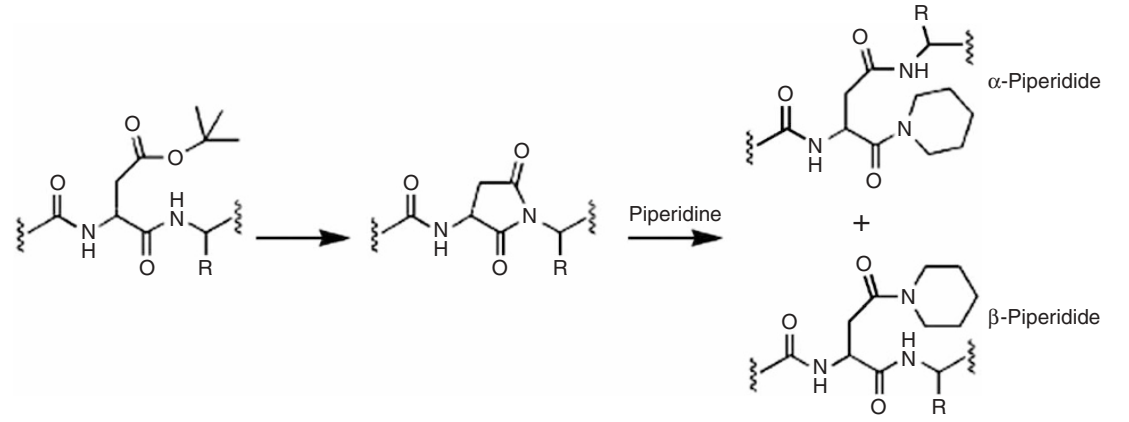

Figure 5 | Aspartimide formation during synthesis of $F_{n} Y$-22mer. Aspartimides result from condensation of an amide with the side chain of a nearby Asp residue, which is protected by a $t$-butyl group. Reaction of piperidine with the aspartimide during Fmoc deblocking yields $\alpha$ - and $\beta$-piperidide-modified peptides. Aspartimide formation is prevented by performing deblocking reactions in the presence of HOBt, as reported previously ${ }^{36}$. 
by breaking up secondary structures ${ }^{36}$. Further, the pseudo-proline moiety is acid-labile and yields the desired $\mathrm{S}_{13}$ and $\mathrm{D}_{14}$ residues after TFA-mediated cleavage of the peptide from the solid-phase resin (vide infra).

- PAUSE POINT At the end of the automated synthesis of the 19-mer peptide, the resin-bound, Fmoc-protected peptide may be stored dry at $-80^{\circ} \mathrm{C}$ for a year.

18| The next three residues may now be coupled manually. Transfer the resin-bound peptide into a capped Econo-pac column. These columns are capped at the top and bottom during the reaction. Remove the Fmoc group from the N-terminal end of the resin-bound nascent peptide by shaking it in the Econo-pac column on a vortexer with a deblocking mixture consisting of $20 \%$ $(\mathrm{v} / \mathrm{v})$ piperidine and 0.1 M HOBt in DMF for 10-12 min. Remove the bottom and top caps to drain the deblocking mixture. Add fresh deblocking mixture and vortex for another 10-12 min. Drain the deblocking solution as before. Use $15 \mathrm{ml}$ of deblocking solution per gram of resin.

19| After deblocking, wash the resin 4-5 times with DMF by adding 7-8 $\mathrm{ml}$ of DMF per gram of resin, vortexing for $\sim 1 \mathrm{~min}$ and draining the DMF from the column by removing the top and bottom caps. After the last wash, blow $\mathrm{N}_{2}$ gas through the column to remove residual DMF completely.

20| Add the next residue ( $\left.\mathrm{Fmoc}-\mathrm{F}_{n} \mathrm{Y}-\mathrm{OH}\right)$ by vortexing the resin-bound peptide for $1 \mathrm{~h}$ with at least 6 equivalents of $\mathrm{N}$-Fmocprotected amino acid, 5.4 equivalents of HATU and 12 equivalents of DIPEA in DMF at final concentrations of $0.5,0.45$ and 1 M, respectively. Prepare this mixture by first dissolving the Fmoc-protected amino acid in the required volume of DMF, followed by HATU and DIPEA. Vortex the vessel for $\sim 10-15 \mathrm{~s}$ to dissolve the components completely; then add these to the resin-bound peptide in the Econo-pac column. (For example, a mixture of 2.5-3 $\mathrm{ml}$ of DMF with Fmoc-protected amino acid, HATU and DIPEA at final concentrations of $0.5,0.45$ and $1 \mathrm{M}$, respectively, is added to $1 \mathrm{~g}$ of resin-bound peptide.) Vortex the mixture at room temperature for $1 \mathrm{~h}$, then wash the resin-bound peptide 2-3 times with DMF as in Step 19.

21 Repeat Steps 18-20 for the 21st amino acid in the sequence (Fmoc-Ser(OtBu)-OH). Then, remove the Fmoc-protecting group of the 21st amino acid as described in Steps 18 and 19.

22| Add the $\mathrm{N}$-terminal Cys residue in its pentafluorophenol-activated and ${ }^{\mathrm{B}}$ Buthio-protected form. Coupling of this residue requires vortexing with 6 equivalents of Fmoc-Cys ( $\left.{ }^{\mathrm{t} B u t h i o}\right)-\mathrm{OPfp}$ and 6 equivalents of HOBt relative to peptide at final concentrations of $0.5 \mathrm{M}$ each for $1.5 \mathrm{~h}$. Wash the resin 2-3 times with DMF as described in Step 19 and deblock the Fmoc-protecting group as described in Steps 18 and 19.

$\triangle$ CRITICAL STEP Cys residues have a propensity to racemize when coupled using DIPEA ${ }^{38}$. To avoid Cys racemization, the $\mathrm{N}$-terminal Cys residue is coupled as an activated OPfp ester obviating the need for a base.

23| Before cleavage of the peptide from the resin, wash the resin-bound peptide 2-3 times with $\mathrm{CH}_{2} \mathrm{Cl}_{2}$ as described in Step 19 for DMF washes. Then, cap the Econo-Pac column at the top, but not at the bottom, and connect the bottom of the column to a vacuum line. Pull a vacuum for 5-10 min to dry the resin completely.

24| Cleave the peptide from the resin by shaking the resin with a solution consisting of $95 \%$ TFA, $2.5 \%$ TIS and $2.5 \%$ water for $4 \mathrm{~h}$. Use $25 \mathrm{ml}$ of cleavage solution per gram of resin.

25 After $4 \mathrm{~h}$, the TFA solution will contain the free peptide. Drain this solution into a $50 \mathrm{ml}$ Falcon tube and wash the resin 2-3 times with a small volume of TFA. Combine the TFA washes with the cleavage solution.

26| Concentrate the peptide by blowing $\mathrm{N}_{2(\mathrm{~g})}$ over the solution until precipitation occurs. At this point, add 8-10 volumes of chilled diethyl ether and incubate the mixture at $4{ }^{\circ} \mathrm{C}$ for $\sim 45 \mathrm{~min}$.

27| Collect the peptide by centrifugation $\left(\sim 5,000 \mathrm{~g}, 10-15 \mathrm{~min}, 4^{\circ} \mathrm{C}\right)$ and discard the supernatant. Wash the peptide once with cold diethyl ether by adding the same volume of cold diethyl ether as in Step 26, incubating for $\sim 5$ min at $4{ }^{\circ} \mathrm{C}$ and discarding the ether after centrifugation. Remove residual ether in vacuo or by placing the Falcon tube uncapped in a hood at room temperature overnight.

PAUSE POINT The peptide may be stored in this form at $-80^{\circ} \mathrm{C}$ for a year.

28| Dissolve the peptide in $0.1 \mathrm{M} \mathrm{NH}_{4} \mathrm{HCO}_{3}(\mathrm{pH} 8.0)$ to a concentration of $\geq 0.3 \mathrm{mM}$.

$\triangle$ CRITICAL STEP Because of the large number of carboxylates in the $F_{n} Y-22 m e r$ (total of six), it is soluble only under mildly basic conditions. This is unusual as most peptides are readily soluble in acid.

29| Purifications on a semipreparative scale may be performed on a Waters XTerra column. Up to $2 \mu$ mol of peptide can be loaded onto this column per injection (5 ml injection loop). Elute the peptide with $0.1 \mathrm{M} \mathrm{NH}_{4} \mathrm{HCO}_{3}(\mathrm{pH} 8.0)$ with a linear 
gradient of $10-20 \%$ MeCN over 5 min followed by a linear gradient of $20-35 \% \mathrm{MeCN}$ over $23 \mathrm{~min}$. Monitor peptide elution by absorbance at $215 \mathrm{~nm}$ and at $\lambda_{\max }$ of specific $\mathrm{F}_{n} \mathrm{Y}$ (Table 1 ). Collect the fractions containing the peptide, remove $\mathrm{MeCN}$ in vacuo by rotary evaporation (water bath temperature set at $25^{\circ} \mathrm{C}$ ) and lyophilize the remaining peptide solution to dryness.

30| The purity of the peptide is assessed using analytical HPLC. A linear gradient of $10-75 \% \mathrm{MeCN}$ over 45 min versus $0.1 \mathrm{M} \mathrm{NH}_{4} \mathrm{HCO}_{3}$ (pH 8.0) is used to elute the peptide from the Jupiter Phenomenex column. A typical profile is shown in Figure 6.

31 Obtain a UV spectrum and MALDI-TOF MS on each purified peptide to ascertain its identity. Table 1 summarizes the absorption maxima and extinction coefficients of $\mathrm{C}$ - and $\mathrm{N}$-terminally blocked $\mathrm{F}_{n} \mathrm{Y}_{\mathrm{s}}$ in the phenol and phenolate forms.

As there are no other Trp or Tyr residues in the peptide sequence, the $F_{n} Y_{s}$ are predominantly responsible for the absorbance in the $\sim 270 \mathrm{~nm}$ region.

32 Finally, the tButhio-protecting group on the N-terminal Cys residue must be removed. To avoid intermolecular disulfide bond formation between two peptides, removal of the ${ }^{\mathrm{t}}$ Buthio group is performed under anaerobic conditions. Disulfide formation is more prevalent from the thiolate form of the Cys residue, predominantly present as the peptide is soluble only under mildly basic conditions. Suspend the lyophilized peptide in $0.1 \mathrm{M} \mathrm{NH}_{4} \mathrm{HCO}_{3}$ (aq.) (pH 8.0) to a final concentration of 1-7 mM and add 0.1 volume of $250 \mathrm{mM}$ Tris ( $\mathrm{pH} \mathrm{8.0).} \mathrm{For} \mathrm{example,} \mathrm{to} \mathrm{deprotect} 5 \mu \mathrm{mol}$ of peptide, suspend it in a $3 \mathrm{ml}$ solution of $0.1 \mathrm{M} \mathrm{NH}_{4} \mathrm{HCO}_{3}(\mathrm{pH} 8.0)$ and add $300 \mu \mathrm{l}$ of $250 \mathrm{mM}$ Tris (pH 8.0). Transfer the solution to a pear-shaped flask and deoxygenate it on a Schlenk line by alternating cycles of degassing, by pulling a vacuum, followed by readdition of argon gas. Six to eight cycles are required for complete degassing. In each cycle, the flask is degassed by pulling a vacuum for $\sim 2-5 \mathrm{~min}$ and then flushed with argon with stirring for $\sim 5 \mathrm{~min}$.

33| Add solid DTT to a 15-fold molar excess over peptide. During this addition, the mixture is briefly exposed to atmosphere. Therefore, degas the mixture again as described in Step 32. Stir the reaction mixture at room temperature for $4 \mathrm{~h}$.

34| After $4 \mathrm{~h}$, transfer the reaction mixture to a dialysis bag and dialyze anaerobically (as described in EQUIPMENT SETUP) against $5 \mathrm{mM}$ potassium phosphate, $\mathrm{pH} 6.0$ (1 liter, 2-3 changes of $4 \mathrm{~h}$ each). After dialysis, transfer the peptide solution to a Falcon tube, freeze and lyophilize to dryness.

PAUSE POINT The purified, dry peptide may be stored at $-80{ }^{\circ} \mathrm{C}$ for a year.

\section{Ligation of $\mathrm{F}_{n} \mathrm{Y}$-22mer(s) to MESNA-activated R2 TIMING 3-4 weeks}

35| Transform pR2-intein-CBD ${ }^{17}$ into BL21-DE3 codon+ cells using instructions provided by the manufacturer.

$\triangle$ CRITICAL STEP For the semisynthesis of R2, the Stratagene codon+ competent cell line yielded optimal expression, purification and radical content. Note that depending on the origin of the intein, codon+ cell lines may not be necessary. To determine whether codon+ cell lines are required, the codon usage of the organism from which the intein originates should be compared to that of E. coli or the organism in which expression is performed.

36| Carry out small and large culture growths with shaking (200 r.p.m.) at $37{ }^{\circ} \mathrm{C}$ in LB containing Amp (100 $\left.\mu \mathrm{g} \mathrm{ml}^{-1}\right)$ and $\mathrm{Cm}$ $\left(50 \mu \mathrm{g} \mathrm{m}^{-1}\right)$. Inoculate a $5 \mathrm{ml} \mathrm{LB} / \mathrm{Amp} / \mathrm{Cm}$ culture (in a $12 \mathrm{ml}$ bacterial culture tube) with a single colony obtained from the transformation in Step 35.

- PAUSE POINT Grow cells to saturation overnight $(\sim 12 \mathrm{~h})$.

37| Dilute $0.5 \mathrm{ml}$ of the saturated small culture into a $100 \mathrm{ml}$ medium culture of LB/Amp/Cm in a $500 \mathrm{ml}$ Erlenmeyer flask.

PAUSE POINT Grow this medium culture to saturation overnight $(\sim 12 \mathrm{~h})$.

38| Finally, inoculate a 10-liter LB/Amp/Cm large culture $(5 \times 2$-liter cultures in 6-liter Erlenmeyer flasks $)$ with $50 \mathrm{ml}$ of the saturated medium culture, and continue growth at $37^{\circ} \mathrm{C}$.

39| When $\mathrm{OD}_{600 \mathrm{~nm}}$ reaches $0.7-0.8$ ( $\sim 4 \mathrm{~h}$ after inoculation), lower the temperature setting to $23^{\circ} \mathrm{C}$. After 15 min, add IPTG to a final concentration of $0.5 \mathrm{mM}$ and continue incubation at $23{ }^{\circ} \mathrm{C}$ for an additional $5-6 \mathrm{~h}$. At this time, harvest the cells by centrifugation $\left(10,000 \mathrm{~g}, 15 \mathrm{~min}, 4^{\circ} \mathrm{C}\right)$; typically a yield of $5 \mathrm{~g}$ wet cell paste per liter culture is obtained. 
$\triangle$ CRITICAL STEP The R2-intein-CBD chimera is insoluble at $37{ }^{\circ} \mathrm{C}$; therefore, expression must be performed at $23{ }^{\circ} \mathrm{C}$. Also, the thioester linkage in the expressed truncated R2 is unstable even at $-80^{\circ} \mathrm{C}$. Therefore, for optimal ligation yields, purification of the truncated R2 construct must be performed within a few days of growth.

40 Resuspend each gram of cell paste in $5 \mathrm{ml}$ of lysis buffer supplemented with $1 \mathrm{mM}$ PMSF and $25 \mathrm{U}$ DNase I. Lyse the cells in a French Pressure Cell at 14,000 p.s.i. with a single passage. To ensure sufficient iron for diiron cluster assembly within R2, dissolve $\mathrm{Fe}^{\mathrm{II}}\left(\mathrm{NH}_{4}\right)_{2}\left(\mathrm{SO}_{4}\right)_{2}$ and sodium ascorbate (5 mg of each per gram cell paste) in $\sim 10 \mathrm{ml}$ of lysis buffer and add this solution dropwise over $10 \mathrm{~min}$ to the crude extract at $4{ }^{\circ} \mathrm{C}$ while stirring. Then, stir the mixture for an additional $15 \mathrm{~min}$. Finally, remove cell debris by centrifugation at $4{ }^{\circ} \mathrm{C}(15,000 \mathrm{~g}, 35 \mathrm{~min})$.

41| Collect the supernatant and load it onto the pre-equilibrated chitin column (see EQUIPMENT SETUP) at a flow rate of 1-3 $\mathrm{ml} \mathrm{min}{ }^{-1}$. A total of $5 \mathrm{ml}$ of chitin resin is required per gram of cell paste.

42 Wash the resin with 30-40 CV of lysis buffer containing $0.2 \mathrm{mM}$ PMSF, followed by 2 CV of cleavage buffer. Then, load the column with $1.5 \mathrm{CV}$ of cleavage buffer containing $100 \mathrm{mM}$ MESNA.

PAUSE POINT Incubate at $4{ }^{\circ} \mathrm{C}$ for $30 \mathrm{~h}$.

$\triangle$ CRITICAL STEP The cleavage efficiency is directly dependent on MESNA concentration and time of incubation. We find that incubation with $100 \mathrm{mM}$ MESNA for $30 \mathrm{~h}$ yields optimal cleavage (5 mg MESNA-activated R2 per gram of cell paste) but gives $Y_{122} \bullet$ radical content of only $\sim 0.3$ per R2. This contrasts with the $1.2 Y_{122} \bullet$ s per R2 generated by recombinant technology. In turn, incubation with a low MESNA concentration and shorter incubation periods, $50 \mathrm{mM}$ and $20 \mathrm{~h}$, respectively, results in low cleavage efficiency ( $3 \mathrm{mg}$ MESNA-activated R2 per gram of cell paste) but higher radical content ( $\sim 0.45$ per R2).

43 After $30 \mathrm{~h}$, elute the MESNA-activated R2 from the chitin column with cleavage buffer. The amount of protein is monitored using the Bradford reagent assay (see manufacturer's instructions). Continue elution until no more protein is detected.

$\triangle$ CRITICAL STEP The amount of MESNA-activated R2 eluting from the column is dependent on the concentration of MESNA and the period of incubation as described above. It is also dependent on the C-terminal residue of truncated R2 containing the MESNA thioester (residue 353, which is a valine in wild-type R2, but a glycine in all of our R2-intein-CBD constructs). Bulky side chains at this position sterically hinder access of the small molecule thiol to the thioester. We have determined cleavage efficiencies of $50 \%, 15 \%$ and $10 \%$, when residue 353 is Gly, Ala and Val, respectively. Because we required $100 \mathrm{mg}$ quantities of semisynthetic R2 for biophysical experiments that we wished to carry out, all our R2 semisyntheses were performed with Gly at residue 353. The cleavage efficiency is also dependent on the small molecule thiol. Ideally, the thiol is a good nucleophile for optimal cleavage and a good leaving group for optimal ligation (vide infra). We found MESNA to yield the best combined cleavage and ligation efficiencies. Although DTT yielded the highest cleavage efficiency, ligation yields were poor. Other thiols tested were $\beta M E$, ethanethiol, thiophenol and benzylmercaptan. Although thiophenol is not expected to be a good cleavage reagent, its use for this purpose has been reported ${ }^{39}$.

44 After elution, concentrate the MESNA-activated R2 to 20-25 $\mathrm{mg} \mathrm{ml}^{-1}$ using an Amicon concentration device with a YM-30 membrane. Then, remove the excess MESNA from the MESNA-activated R2 using Sephadex G-25 chromatography in cleavage buffer. Because this desalting step results in protein dilution, concentrate the MESNA-activated R2 again to 20-25 mg ml ${ }^{-1}$ using a YM-30 Centriprep protein concentrator.

45 Degas the protein on a Schlenk line with ten cycles of vacuum degassing for 5-10 s followed by argon fill for 1 min with stirring. Transfer the protein sample into the glove box for the ligation step. Transfer the lyophilized peptide to the glove box as well.

46| Set up the ligation reaction by adding peptide to a final concentration of $2 \mathrm{mM}$ to the degassed, truncated, MESNA-activated R2. Then add 0.1 volumes of 1.5 M HEPES and 0.4 mM EDTA (pH 7.9). Typically, the ligation reaction contains, in a final volume of $3 \mathrm{ml}, 20 \mathrm{mg} \mathrm{ml}^{-1}$ MESNA-activated R2 $(0.7 \mu \mathrm{mol})$ and $2 \mathrm{mM}$ peptide $(6 \mu \mathrm{mol})$.

- PAUSE POINT Incubate the reaction mixture at $4{ }^{\circ} \mathrm{C}$ in the glove box for $36 \mathrm{~h}$.

$\triangle$ CRITICAL STEP Note that stirring is not recommended as it induces protein precipitation under these conditions. Instead, gently swirl the flask 3-4 times during the incubation period.

$\triangle$ CRITICAL STEP As described in Step 43, the small molecule thiol of choice is one that yields high cleavage and ligation efficiencies. Previously, Kent and co-workers ${ }^{40}$ reported the use of small molecule thiol catalysts for the ligation reaction. We tested the ability of thiophenol and $p$-nitrothiophenol to function in this capacity using the truncated, MESNA-activated R2. However, we observed no improvement in the ligation yield.

47| Divide the $\sim 3 \mathrm{ml}$ ligation mixture into $1 \mathrm{ml}$ aliquots in $1.5 \mathrm{ml}$ Eppendorf tubes, flash-freeze in liquid $\mathrm{N}_{2}$ and store at $-80{ }^{\circ} \mathrm{C}$. $\square$ PAUSE POINT The ligation mixture is stable at $-80{ }^{\circ} \mathrm{C}$ for a year.

48| The unreacted peptide used in the ligation often forms an intermolecular disulfide bridge with the ligated peptide that generates full-length R2 (see ref. 17) To reduce this disulfide bond, thaw an aliquot of the ligation mixture and add DTT to a final concentration of $5 \mathrm{mM}$. Incubate the reaction mixture at $4{ }^{\circ} \mathrm{C}$ for $20 \mathrm{~min}$. Then remove the excess peptide from R2 using concentration-dilution cycles in a centriprep protein concentrator device. 
$\triangle$ CRITICAL STEP The removal of the adventitiously bound peptide is critical for experiments performed with R2, as the C-terminal peptide provides the key binding sites for interaction with R1. Note that depending on the peptide sequence, it may not be removed by concentration-dilution cycles through a membrane-this possibility needs to be investigated for the peptide of interest (e.g., by non-reducing SDS-PAGE). Should removal not occur by concentration-dilution cycles, then Sephadex G-25 chromatography under reducing conditions may be used to remove the peptide. Furthermore, the ensuing purification on a MonoQ column (Step 49) is carried out under reducing conditions to ensure complete removal of adventitiously bound peptide.

49| Inject $10-20 \mathrm{mg}$ of the ligation reaction onto a MonoQ anion exchange column (2 $\mathrm{ml}$ injection loop). Elute R2 with a linear $\mathrm{NaCl}$ gradient-a typical elution profile is shown in

Figure 7. Because of the negative charge associated with the C-terminal 22 amino acids of R2, the heterodimer can be separated from the two homodimers. Pool the desired fractions

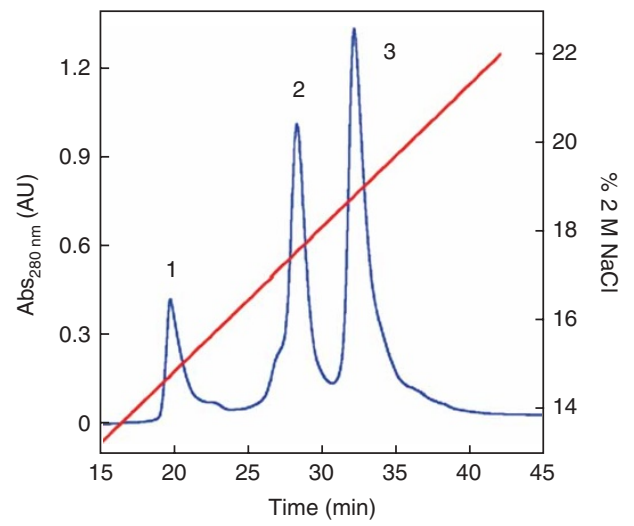

Figure 7 | MonoQ elution profile after ligation of 3,5- $\mathrm{F}_{2} \mathrm{Y}-22 \mathrm{mer}$ to MESNA-activated truncated R2 (ref. 18). Incomplete ligation necessitates separation of three products, the truncated homodimer, 1 , the heterodimeric protein, 2, consisting of a truncated protomer and a full-length protomer and the full-length homodimer, 3, consisting of two full-length protomers. This separation is accomplished using a MonoQ anion exchange column eluting with a linear gradient of 0.2-0.44 M NaCl over $37 \mathrm{~min}$ (refs. 17,18).

(corresponding to peaks 2 and 3 in Fig. 7), concentrate to $\sim 150 \mu \mathrm{M}$ and store at $-80{ }^{\circ} \mathrm{C}$. Typically, $10 \mathrm{~g}$ of wet cell paste yielded $50 \mathrm{mg}$ of truncated MESNA-activated R2, which after ligation yielded 15-20 mg of full-length R2.

PAUSE POINT $F_{n} Y-R 2$ may be safely stored at $-80{ }^{\circ} \mathrm{C}$ for several years.

50| Characterize the semisynthesized R2s by SDS-PAGE and ESI-MS under positive mode via direct infusion (not via LC-MS). The MS data can establish that a peptide of 22 amino acids containing the $F_{n} Y$ of interest has been added.

? TROUBLESHOOTING

\section{TIMING}

The timing for incorporation of a single $F_{n} Y$ into $R 2$ is indicated below. Note that synthesis of $F_{4} Y$ requires 4 weeks.

Reagent and equipment setup (including expression and purification of TPL): 1 month

Synthesis and purification of an $\mathrm{F}_{n} \mathrm{Y}$ (other than $\mathrm{F}_{4} \mathrm{Y}$ ) in Figure 2: 1 week

Synthesis and purification of Fmoc- $F_{n} Y$ and $F_{n} Y$-22mer: 3 weeks

Semisynthesis and purification of $F_{n} Y-R 2$ : 3-4 weeks

\section{? TROUBLESHOOTING}

Troubleshooting advice can be found in Table 3 .

TABLE 3 | Troubleshooting table.

\begin{tabular}{lll}
\hline Problem & Possible reason & Solution \\
\hline No $F_{n} Y$ & Low or no TPL activity & $\begin{array}{l}\text { TPL activity may be lost when stored at }-80^{\circ} \mathrm{C} \text { for prolonged periods } \\
\text { of time: perform TPL activity assays } \mathrm{s}^{32,33}\end{array}$
\end{tabular}

Low Fmoc- $\mathrm{F}_{n} \mathrm{Y}-\mathrm{OH}$ yields $\quad$ Fmoc-OSu hydrolyzed

Fmoc-OSu is susceptible to hydrolysis-ensure that it is stored dry at $-20{ }^{\circ} \mathrm{C}$

Low coupling yields in peptide synthesis HATU decomposed

HATU decomposes fairly rapidly if not stored desiccated at $<5{ }^{\circ} \mathrm{C}$

HOBt not present in Fmoc-decoupling mixture

Low ligation yield
Ensure that HOBt is present in the decoupling mixture when the peptide is made manually or on the synthesizer

Perform the purification within a few days of expression. Alternatively, the cleavage time with MESNA may be lowered

Intermolecular disulfide bond formation in peptides

Incomplete removal of tButhio-protecting group
Repeat Steps 32-34 and ensure they are performed under anaerobic conditions

Repeat Steps 32-34 and ensure they are performed under anaerobic conditions. Alternatively, higher DTT concentrations may be employed 


\section{ANTICIPATED RESULTS}

A typical 1 liter enzymatic synthesis of 3,5- $\mathrm{F}_{2} \mathrm{Y}$ yields $1.7 \mathrm{~g}$ of the desired product ( $80 \%$ yield). Addition of the Fmoc-protecting group by the described procedure yields $\mathrm{Fmoc}-3,5-\mathrm{F}_{2} \mathrm{Y}-\mathrm{OH}$ in good yield $(85 \%)$. The $3,5-\mathrm{F}_{2} \mathrm{Y}-22 \mathrm{mer}$ is synthesized by a combination of automatic and manual SPPS. After purification and deprotection of the ${ }^{\mathrm{t}}$ Buthio-protecting group of the $\mathrm{N}$-terminal Cys, $4.5 \mu \mathrm{mol}$ of 3,5- $\mathrm{F}_{2} \mathrm{Y}-22 \mathrm{mer}$ is obtained from a theoretical yield of $6 \mu \mathrm{mol}$ ( $75 \%$ yield). Ligation of $4.5 \mu \mathrm{mol}$ of peptide to $45 \mathrm{mg}(0.52 \mu \mathrm{mol})$ of MESNA-activated, truncated R2 and subsequent purification yields $20 \mathrm{mg}(0.23 \mu \mathrm{mol})$ of full-length homodimeric 3,5- $\mathrm{F}_{2} \mathrm{Y}-\mathrm{R} 2$. SDS-PAGE and ESI-MS analyses confirm incorporation of 3,5- $\mathrm{F}_{2} \mathrm{Y}$.

ACKNOWLEDGMENTS We thank Professor Robert Phillips for the generous gift of the plasmid pTZTPL used for expressing the enzyme TPL, Chia-Hung Wu for helpful comments on the manuscript and the National Institutes of Health for support (GM29595).

COMPETING INTEREST STATEMENT The authors declare no competing financial interests.

Published online at http://www.natureprotocols.com

Rights and permissions information is available online at http://npg.nature.com/ reprintsandpermissions

1. Stubbe, J. \& van der Donk, W.A. Protein radicals in enzyme catalysis. Chem. Rev. 98, 705-762 (1998).

2. Jordan, A. \& Reichard, P. Ribonucloeotide reductases. Annu. Rev. Biochem. 67, 71-98 (1998).

3. Nordlund, P. \& Reichard, P. Ribonucleotide reductases. Annu. Rev. Biochem. $\mathbf{7 5}$ 681-706 (2006).

4. Stubbe, J. \& Riggs-Gelasco, P. Harnessing free radicals: formation and function of the tyrosyl radical in ribonucleotide reductase. Trends Biochem. Sci. 23, 438-443 (1998).

5. Stubbe, J., Nocera, D.G., Yee, C.S. \& Chang, M.C. Radical initiation in the class I ribonucleotide reductase: long-range proton-coupled electron transfer? Chem. Rev. 103, 2167-2201 (2003).

6. Uhlin, U. \& Eklund, H. Structure of ribonucleotide reductase protein R1. Nature 370, 533-539 (1994).

7. Nordlund, P., Sjöberg, B.M. \& Eklund, H. Three-dimensional structure of the free radical protein of ribonucleotide reductase. Nature 345, 593-598 (1990).

8. Högbom, M. et al. Displacement of the tyrosyl radical cofactor in ribonucleotide reductase obtained by single-crystal high field EPR and 1.4- $\AA$ x-ray data. Proc. Natl. Acad. Sci. USA 100, 3209-3214 (2003).

9. Ekberg, M., Sahlin, M., Eriksson, M. \& Sjöberg, B.M. Two conserved tyrosine residues in protein $\mathrm{R} 1$ participate in an intermolecular electron transfer in ribonucleotide reductase. J. Biol. Chem. 271, 20655-20659 (1996).

10. Ekberg, M. et al. Preserved catalytic activity in an engineered ribonucleotide reductase R2 protein with a nonphysiological radical transfer pathway. J. Biol. Chem. 273, 21003-21008 (1998).

11. Rova, U. et al. Evidence by site-directed mutagenesis supports long-range electron transfer in mouse ribonucleotide reductase. Biochemistry 34, 4267-4275 (1995).

12. Rova, U., Adrait, A., Potsch, S., Gräslund, A. \& Thelander, L. Evidence by mutagenesis that Tyr370 of the mouse ribonucleotide reductase R2 protein is the connecting link in the intersubunit radical transfer pathway. J. Biol. Chem. 274, 23746-23751 (1999).

13. Ekberg, M., Birgander, P. \& Sjöberg, B.M. In vivo assay for low-activity mutant forms of Escherichia coli ribonucleotide reductase. J. Bacteriol. 185, 1167-1173 (2003).

14. Seyedsayamdost, M.R., Reece, S.Y., Nocera, D.G. \& Stubbe, J. Mono-, di-, tri-, and tetra-substituted fluorotyrosines: new probes for enzymes that use tyrosyl radicals in catalysis. J. Am. Chem. Soc. 128, 1569-1579 (2006).

15. Pesavento, R.P. \& van der Donk, W.A. Tyrosyl radical cofactors. Adv. Prot. Chem. 58, 317-385 (2001).

16. Hoganson, C.W. \& Tommos, C. The function and characteristics of tyrosyl radical cofactors. Biochim. Biophys. Acta 1655, 116-122 (2004).

17. Yee, C.S., Seyedsayamdost, M.R., Chang, M.C., Nocera, D.G. \& Stubbe, J. Generation of the R2 subunit of ribonucleotide reductase by intein chemistry: insertion of 3-nitrotyrosine at residue 356 as a probe of the radical initiation process. Biochemistry 42, 14541-14552 (2003).
18. Seyedsayamdost, M.R., Yee, C.S., Reece, S.Y., Nocera, D.G. \& Stubbe, J. pH rate profiles of $\mathrm{F}_{n} \mathrm{Y}_{356}-\mathrm{R} 2 \mathrm{~s}(n=2,3,4)$ in Escherichia coli ribonucleotide reductase: evidence that $\mathrm{Y} 356$ is a redox-active amino acid along the radical propagation pathway. J. Am. Chem. Soc. 128, 1562-1568 (2006).

19. Paulus, H. Protein splicing and related forms of protein autoprocessing. Annu. Rev. Biochem. 69, 447-496 (2000).

20. Cooper, A.A. \& Stevens, T.H. Protein splicing: self-splicing of genetically mobile elements at the protein level. Trends Biochem. Sci. 20, 351-356 (1995).

21. Kane, P.M. et al. Protein splicing converts the yeast TFP1 gene product to the 69-kD subunit of the vacuolar $\mathrm{H}^{+}$-adenosine triphosphatase. Science 250 , 651-657 (1990).

22. Muralidharan, V. \& Muir, T.W. Protein ligation: an enabling technology for the biophysical analysis of proteins. Nat. Methods 3, 429-438 (2006).

23. Perler, F.B. Protein splicing mechanisms and applications. IUBMB Life 57, 469-476 (2005).

24. Chong, S. et al. Protein splicing involving the Saccharomyces cerevisiae VMA intein. J. Biol. Chem. 271, 22159-22168 (1996).

25. Perler, F.B., Xu, M.Q. \& Paulus, H. Protein splicing and autoproteolysis mechanisms. Curr. Opin. Chem. Biol. 1, 292-299 (1997).

26. Chong, S. et al. Single-column purification of free recombinant proteins using a self-cleavable affinity tag derived from a protein splicing element. Gene 192, 271-281 (1997).

27. Wang, L. \& Schultz, P.G. Expanding the genetic code. Angew. Chem. Int. Ed. 44 34-66 (2005).

28. Xie, J. \& Schultz, P.G. An expanding genetic code. Methods 36, 227-238 (2005)

29. Muir, T.W. Semisynthesis of proteins by expressed protein ligation. Annu. Rev. Biochem. 72, 249-289 (2003).

30. Hofman, R.M. \& Muir, T.W. Recent advances in the application of expressed protein ligation to protein engineering. Curr. Opin. Biotechnol. 13, 297-303 (2002).

31. Pellois, J.P. \& Muir, T.W. Semisynthetic proteins in mechanistic studies: using chemistry to go where nature can't. Curr. Opin. Chem. Biol. 10, 487-491 (2006).

32. Kim, K. \& Cole, P.A. Kinetic analysis of a protein tyrosine kinase reaction transition state in the forward and reverse directions. J. Am. Soc. Chem. 120, 6851-6858 (1998).

33. Chen, H., Gollnick, P. \& Phillips, R.S. Site-directed mutagenesis of His $343 \rightarrow$ Ala in Citrobacter freundii tyrosine phenol-lyase. Effects on the kinetic mechanism and rate-determining step. Eur. J. Biochem. 229, 540-549 (1995).

34. Phillips, R.S., Ravichandran, K. \& Von Tersch, R.L. Synthesis of L-tyrosine from phenol and $S$-(o-nitrophenyl)-L-cysteine catalysed by tyrosine phenol-lyase. Enzyme Microb. Technol. 11, 80-83 (1989).

35. Lapatsanis, L., Milias, G., Froussios, K. \& Kolovos, M. Synthesis of N-2,2,2(trichloroethoxycarbonyl)-L-amino acids and $\mathrm{N}$-(9-fluorenyl-methoxycarbonyl)$\mathrm{L}$-amino acids involving succinimidoxy anion as a leaving group in amino acid protection. Synthesis 1983, 671-673 (1983).

36. Mutter, M. et al. Pseudo-prolines (psi Pro) for accessing "inaccessible" peptides. Pept. Res. 8, 145-153 (1995).

37. Lauer, J.L., Fields, C.G. \& Fields, G.B. Sequence dependence of aspartimide formation during 9-flourenylmethoxycarbonyl solid-phase peptide synthesis. Lett. Pept. Sci. 1, 197-205 (1995).

38. Han, Y., Albericio, F. \& Barany, G. Occurrence and minimization of cysteine racemization during stepwise solid-phase peptide synthesis. J. Org. Chem. 62, 4307-4312 (1997).

39. Xu, R., Ayers, B., Cowburn, D. \& Muir, T.W. Chemical ligation of folded recombinant proteins: segmental isotopic labeling of domains for NMR studies. Proc. Natl. Acad. Sci. USA 96, 388-393 (1999).

40. Dawson, P.E., Churchill, M.J., Ghadiri, M.R. \& Kent, S.B.H. Modulation of reactivity in native chemical ligation through the use of thiol additives. J. Am. Chem. Soc. 119, 4325-4329 (1997). 